\title{
Subcellular localisation and composition of intramuscular triacylglycerol influence insulin sensitivity in humans
}

\author{
Darcy Kahn ${ }^{1}$ (1) Leigh Perreault ${ }^{1} \cdot$ Emily Macias $^{1} \cdot$ Simona Zarini $^{1} \cdot$ Sean A. Newsom ${ }^{2} \cdot$ Allison Strauss $^{1}$. \\ Anna Kerege ${ }^{1} \cdot$ Kathleen Harrison $^{1} \cdot$ Janet Snell-Bergeon ${ }^{1} \cdot$ Bryan C. Bergman $^{1}$ (D)
}

Received: 8 May 2020 / Accepted: 25 August 2020 / Published online: 31 October 2020

(C) Springer-Verlag GmbH Germany, part of Springer Nature 2020

\begin{abstract}
Aims/hypothesis Subcellular localisation is an important factor in the known impact of bioactive lipids, such as diacylglycerol and sphingolipids, on insulin sensitivity in skeletal muscle; yet, the role of localised intramuscular triacylglycerol (IMTG) is yet to be described. Excess accumulation of IMTG in skeletal muscle is associated with insulin resistance, and we hypothesised that differences in subcellular localisation and composition of IMTG would relate to metabolic health status in humans.

Methods We evaluated subcellular localisation of IMTG in lean participants, endurance-trained athletes, individuals with obesity and individuals with type 2 diabetes using LC-MS/MS of fractionated muscle biopsies and insulin clamps.

Results Insulin sensitivity was significantly different between each group (athletes>lean>obese>type 2 diabetes; $p<0.001$ ). Sarcolemmal IMTG was significantly greater in individuals with obesity and type 2 diabetes compared with lean control participants and athletes, but individuals with type 2 diabetes were the only group with significantly increased saturated IMTG. Sarcolemmal IMTG was inversely related to insulin sensitivity. Nuclear IMTG was significantly greater in individuals with type 2 diabetes compared with lean control participants and athletes, and total and saturated IMTG localised in the nucleus had a significant inverse relationship with insulin sensitivity. Total cytosolic IMTG was not different between groups, but saturated cytosolic IMTG species were significantly increased in individuals with type 2 diabetes compared with all other groups. There were no significant differences between groups for IMTG concentration in the mitochondria/endoplasmic reticulum.

Conclusions/interpretation These data reveal previously unknown differences in subcellular IMTG localisation based on metabolic health status and indicate the influence of sarcolemmal and nuclear IMTG on insulin sensitivity. Additionally, these studies suggest saturated IMTG may be uniquely deleterious for muscle insulin sensitivity.
\end{abstract}

Keywords Athlete's paradox $\cdot$ Diabetes $\cdot$ Insulin sensitivity $\cdot$ Intramuscular triacylglycerol $\cdot$ Lipid composition $\cdot$ Skeletal muscle

\author{
Abbreviations \\ CTRC Clinical Translational Research Center \\ DAG Diacylglycerol \\ IMTG Intramuscular triacylglycerol \\ $R_{\mathrm{d}} \quad$ Rate of disappearance
}

Supplementary Information The online version of this article (https:// doi.org/10.1007/s00125-020-05315-0) contains peer-reviewed but unedited supplementary material, which is available to authorised users.

Bryan C. Bergman

Bryan.Bergman@ cuanschutz.edu

1 Division of Endocrinology, Metabolism, and Diabetes, University of Colorado Anschutz Medical Campus, Aurora, CO, USA

2 Oregon State University, Corvallis, OR, USA

\section{Introduction}

Many studies have linked intramuscular triacylglycerol (IMTG) content to insulin resistance and type 2 diabetes [1-4], and while it has been suggested that IMTG may be causally associated with insulin resistance, this hypothesis has not been upheld. For instance, endurance-trained athletes have similar IMTG content to individuals with type 2 diabetes, yet are very insulin sensitive [5], and the effect of insulinsensitising exercise training interventions on IMTG content in individuals with obesity is varied and inconclusive [6-12]. Interestingly, studies have shown that synthesis rates of IMTG are linearly related to insulin sensitivity and it has been suggested that IMTG may indirectly influence muscle metabolism. Increased partitioning of fatty acids towards IMTG protects against the accumulation of harmful lipid mediators, 


\section{Research in context}

\section{What is already known about this subject?}

- Increased intramuscular triacylglycerol (IMTG) accumulation is associated with insulin resistance in humans

- Within skeletal muscle tissue, subsarcolemmal localisation of IMTG is associated with insulin resistance, while intermyofibrillar IMTG is not

- Bioactive lipids linked to insulin resistance localise within different subcellular compartments in skeletal muscle

\section{What is the key question?}

- Are differences in IMTG composition and subcellular localisation related to insulin sensitivity in humans?

\section{What are the new findings?}

- Sarcolemmal and nuclear accumulation of IMTG negatively correlates with insulin sensitivity

- There is no relationship between mitochondrial/endoplasmic reticulum IMTG accumulation and insulin sensitivity

- Saturated fatty acids stored as IMTG in the cytosolic, sarcolemmal and nuclear compartments are positively related to insulin resistance

How might this impact on clinical practice in the foreseeable future?

- These data provide insight into the specific types and location of triacylglycerol that should be modified therapeutically to decrease lipotoxicity and the risk of type 2 diabetes

such as diacylglycerol (DAG) and ceramide [13-16]. For example, it has been shown that increased accumulation of IMTG by acute exercise results in the reduction of DAG synthesis, as well as decreased inflammatory signalling and increased insulin sensitivity in humans [17]. While the pivotal role that bioactive lipids, such as DAG and ceramide, play in mediating fatty acid-associated insulin resistance in skeletal muscle is well defined, the participation of IMTG, which may be indirect, is less well known.

Lipid composition is fundamental to the impact of bioactive lipids, such as DAG and ceramide, on insulin sensitivity; however, this relationship is not definitive in regard to IMTG [18-23]. While several groups have shown an association between increased saturated IMTG and insulin resistance in humans [24-26], others have reported that no relationship was observed [19]. Additionally, IMTG composition does not change with exercise training and does not appear to be related to insulin sensitivity in previous studies [10, 13, 27, 28]. Therefore, there is a lack of consistency in the literature as to the potential importance of IMTG composition in regulating insulin sensitivity in humans.

Bioactive lipids linked to insulin resistance localise within different compartments in skeletal muscle, and alterations in subcellular localisation appear to influence insulin sensitivity [18, 29-32]. Transmission electron microscopy studies have shown that IMTG is also compartmentalised in skeletal muscle and that differences in localisation may impact muscle metabolism. While subsarcolemmal IMTG was found to be negatively related to insulin sensitivity, intermyofibrillar IMTG was unrelated or positively related to insulin sensitivity
[33-36]. Exercise training has also been shown to have an impact on IMTG localisation, decreasing subsarcolemmal IMTG distribution [37-39] and increasing co-localisation with mitochondria $[35,40]$. The physical location of IMTG droplets relative to mitochondria is important, as their close proximity may facilitate oxidation of IMTG [40]. While localisation of IMTG within skeletal muscle appears to have an impact on insulin sensitivity, a more detailed subcellular analysis of this relationship has not been performed.

The goal of this study was to elucidate IMTG composition and subcellular localisation across the spectrum of insulin sensitivity and metabolic health in humans. In order to accomplish this, we fractionated muscle biopsies from humans spanning the physiological range of insulin sensitivity into sarcolemmal, cytosolic, mitochondrial/endoplasmic reticulum and nuclear compartments and analysed IMTG composition in each fraction. We also conducted lipidomic analysis and hyperinsulinaemic-euglycaemic clamps in participants.

\section{Methods}

\section{Participants}

Fourteen lean control participants, 16 lean endurance-trained athletes, 15 individuals with obesity and 12 individuals with type 2 diabetes were included in the study, which has been published previously [29]. Participants gave written informed consent, and were excluded if they had: BMI $<20 \mathrm{~kg} / \mathrm{m}^{2}$ or $>25 \mathrm{~kg} / \mathrm{m}^{2}$ for the lean and athlete groups, and BMI $<30 \mathrm{~kg} /$ 
$\mathrm{m}^{2}$ or $>40 \mathrm{~kg} / \mathrm{m}^{2}$ for the obese and type 2 diabetes groups; fasting triacylglycerol levels $>8.3 \mathrm{mmol} / \mathrm{l}$; or liver, kidney, thyroid or lung disease or type 1 diabetes. Individuals with type 2 diabetes were excluded from the study if they used insulin and/or thiazolidinediones due their known confounding impact on IMTG concentration. All other medications were permissible but washed out for 2 weeks prior to metabolic testing.

Fasting and $2 \mathrm{~h}$ OGTT plasma glucose was measured from all consented participants to screen for type 2 diabetes during preliminary testing, and individuals were classified into study groups based on criteria set by the American Diabetes Association. Participants with obesity with fasting plasma glucose levels $\geq 7.0 \mathrm{mmol} / 1$ and/or $2 \mathrm{~h}$ OGTT values $\geq 11.1 \mathrm{mmol} / \mathrm{l}$ were placed in the type 2 diabetes study group, while participants with obesity with fasting plasma glucose values $<7.0 \mathrm{mmol} / 1$ and/or $2 \mathrm{~h}$ OGTT values $<11.1 \mathrm{mmol} / 1$ were included in the obese study group. Lean control participants, as well as individuals with obesity and type 2 diabetes were sedentary (engaged in planned physical activity for $<2 \mathrm{~h} /$ week). Endurance athletes were master's athletes training for cycling and triathlon competitions with a mean $( \pm$ SEM) training history of $10.6 \pm 1.9$ years at $12.7 \pm 0.8 \mathrm{~h} /$ week. None of the individuals with obesity, lean participants, or athletes were taking medications. Participants were weight stable in the 6 months prior to the study.

This study was approved by the Colorado Multiple Institution Review Board at the University of Colorado Denver (Denver, CO, USA).

\section{Preliminary testing}

Participants reported to the Clinical Translational Research Center (CTRC) following a $12 \mathrm{~h}$ overnight fast, where they were given a health and physical examination, followed by a fasting blood draw, and a standard 75 g OGTT to verify glucose tolerance. Body composition was determined using dual energy $x$-ray absorptiometry (DEXA) analysis (Lunar DPX-IQ, Lunar Corporation, Madison, WI, USA).

\section{Diet and exercise control}

Diet was not controlled in this study to avoid confounding from acute dietary changes on muscle lipid composition. Participants were asked to refrain from planned physical activity for $48 \mathrm{~h}$ before the metabolic study.

\section{Insulin clamp study}

Volunteers spent the night at the CTRC to ensure compliance with the overnight fast. After a $12 \mathrm{~h}$ overnight fast, an antecubital vein in one arm was cannulated for infusions of glucose-stable isotopes, insulin and 'spiked' dextrose, and a retrograde dorsal hand vein in the contralateral side was catheterised for blood sampling via the heated hand technique. A primed continuous infusion of $\left[6,6-{ }^{2} \mathrm{H}_{2}\right]$ glucose and $\left[\mathrm{U}^{13}\right.$ C]glucose was initiated at $0.04 \mathrm{mg} \mathrm{kg}^{-1} \mathrm{~min}^{-1}$ and continued throughout a $2 \mathrm{~h}$ equilibrium period and the $3 \mathrm{~h}$ insulin clamp. Blood samples for determination of baseline substrate concentrations were drawn during the final $30 \mathrm{~min}$ of the $2 \mathrm{~h}$ tracer equilibration, before the clamp. After $2 \mathrm{~h}$ of tracer equilibration, a percutaneous needle biopsy $(\sim 150 \mathrm{mg})$ was taken from midway between the greater trochanter of the femur and the patella. Muscle was immediately flash frozen in liquid nitrogen and stored at $-80^{\circ} \mathrm{C}$, until analysis. Skeletal muscle samples were dissected free of extramuscular fat on ice, as previously described [41]. A hyperinsulinaemiceuglycaemic clamp was then initiated and continued for the next $3 \mathrm{~h}$, using the method of DeFronzo et al. [42]. Briefly, a primed continuous infusion of insulin was administered at $40 \mathrm{mU} \mathrm{m}{ }^{-2} \mathrm{~min}^{-1}$ for $3 \mathrm{~h}$. A variable infusion of $20 \%$ (wt/ vol.) dextrose was infused to maintain a blood glucose concentration of $\sim 5 \mathrm{mmol} / \mathrm{l}$. The dextrose infusion used to maintain euglycaemia was labelled with $\left[6,6-{ }^{2} \mathrm{H}_{2}\right]$ glucose (Cambridge Isotope Laboratories, USA) to maintain stable enrichment of plasma glucose [43]. Arterialised blood was sampled every $5 \mathrm{~min}$ for bedside determination of glucose concentration (Analox, Lunenburg, MA, USA) and the dextrose infusion adjusted as necessary. During the last $30 \mathrm{~min}$ of the clamp, measurements of respiratory gas exchange were made via indirect calorimetry. Enzymatic assays were used to measure blood glucose and triacylglycerol concentrations (Olympus AU400e Chemistry Analyzer, Olympus America, Center Valley, PA, USA).

\section{Muscle fractionation}

To ensure specific measurement of intracellular lipids, muscle biopsies were first dissected free from extramuscular adipose tissue and then 45-60 mg of frozen muscle was homogenised using a Teflon-glass homogeniser (Caframo Lab Solutioins, Canada) for $1 \mathrm{~min}$, on ice at $600 \mathrm{rpm}$, in fractionation buffer ( $250 \mathrm{mmol} / 1$ sucrose; $5 \mathrm{mmol} / 1 \mathrm{MgCl}_{2} ; 1 \mathrm{mmol} / \mathrm{l}$ EDTA; $20 \mathrm{mmol} / \mathrm{l} \mathrm{Tris-Cl} ; 40 \mathrm{mmol} / \mathrm{l} \mathrm{KCl} ; \mathrm{pH}$ 7.4). Samples were then centrifuged for $1 \mathrm{~h}$ at 100,000 $\mathrm{g}$ and the supernatant, containing the cytosolic compartment, was saved. The pellet was resuspended in $1 \mathrm{ml}$ of the fractionation buffer by pipetting the pellet with a p1000 pipette (Eppendorf, Germany) until mixed, followed by 10 aspirations through an 18 gauge needle before sitting it on ice for $30 \mathrm{~min}$. The sample was then loaded onto the top of an Optiprep (Alere Technologies, Norway) gradient containing $5 \mathrm{ml}$ of $16 \%, 1.5 \mathrm{ml}$ of $20 \%, 1.5 \mathrm{ml}$ of $25 \%$ and $2 \mathrm{ml}$ of $30 \%$ (wt/vol.) Optiprep buffer, diluted with fractionation buffer. The gradient was then spun using an NVT65 rotor (Beckman Coulter, USA) at $60,000 \mathrm{~g}$ for $1 \mathrm{~h}$ at $4^{\circ} \mathrm{C}$. The top $3 \mathrm{ml}$ were saved, containing the sarcolemmal fraction, the next 
$1.5 \mathrm{ml}$ were not saved, and the next $3 \mathrm{ml}$ containing the mitochondrial/endoplasmic reticulum fraction, and the final $2 \mathrm{ml}$ above the $30 \%$ (wt/vol.) Optiprep buffer containing the nuclear fraction, were collected. Aliquots of each fraction were saved and run for protein content using a Pierce BCA Assay (Thermo Fisher Scientific, Rockford, IL, USA).

\section{Lipidomics analysis}

After the Tri-C17:0 triacylglycerol internal standard (Avanti Polar Lipids, USA) was added to each fraction, samples were lipid extracted using previously described methods [29]. IMTG species were analysed by an Agilent 1100 HPLC system (Agilent, USA) connected to an API 2000 triple quadrupole mass spectrometer (Sciex, USA) [44]. Concentration was determined by comparing ratios of unknowns to Tri-C17:0 triacylglycerol and then these area ratios were compared with standard curves representing typical triacylglycerol species run with each sample set. When performing muscle fractionation, lipid extraction and LC-MS/MS analysis, samples from each study group (athlete, lean, individuals with obesity and individuals with type 2 diabetes) were run simultaneously to avoid the possibility of confounding our findings due to batch effects.

\section{Statistical analysis}

Data are presented as mean \pm SEM. Differences in total IMTG content and composition data between groups were analysed using a one-way ANOVA (SPSS, Chicago, IL, USA). Significant differences in IMTG content between compartments and in individual localised IMTG species between groups within a compartment were adjusted for multiple comparisons using the Benjamini-Hochberg procedure [45]. When significant differences were detected, groups were compared using two-tailed Student's $t$ tests. Significant relationships between localised IMTG species and insulin sensitivity were determined using Pearson's correlation coefficient and were adjusted for multiple comparisons using the Benjamini-Hochberg procedure.

\section{Results}

\section{Demographics, plasma markers and insulin sensitivity}

Participant demographics, plasma markers and insulin sensitivity have been previously reported [29] and a summary of those findings are shown in Table 1. BMI and body fat content were significantly lower in the athlete and lean groups as compared with individuals with obesity and type 2 diabetes, as expected. Fasting and $2 \mathrm{~h}$ plasma glucose concentrations were significantly greater in individuals with type 2 diabetes compared with the other groups. Preliminary screening results revealed one individual in the obese study group with impaired fasting glucose, while the rest of the individuals with obesity had normal glucose tolerance. Results on subcellular localisation of DAG and sphingolipids in this cohort have already been published [29]. Insulin sensitivity, which was measured by the rate of disappearance of glucose (glucose $R_{\mathrm{d}}$ ) using $\left[6,6{ }^{2} \mathrm{H}_{2}\right]$-glucose during the insulin clamp, was significantly different between each group and largely reflected differences in muscle disposal (athletes $>$ lean $>$ obese $>$ type 2 diabetes; $p<0.001$; Table 1). Our four groups of volunteers generated a dataset with individuals spanning the physiological range of insulin sensitivity.

\section{Whole muscle IMTG content}

To determine whole muscle IMTG content, the sum of triacylglycerol levels in each fraction was normalised to protein content to account for the amount of muscle analysed. We found that whole muscle IMTG content was lowest in athletes and lean individuals, and significantly greater in individuals with obesity and individuals with type 2 diabetes (Fig. 1a). We also found that individuals with type 2 diabetes had significantly greater saturated IMTG content compared with all other groups (Fig. 1b). There was an inverse relationship between clamp glucose disposal rate $\left(R_{\mathrm{d}}\right)$ and total $\operatorname{IMTG}(p=0.01$; data not shown), and the relationship was even stronger for clamp glucose $R_{\mathrm{d}}$ and saturated IMTG ( $p=0.001$; Fig. $1 \mathrm{c}$ ).

\section{Subcellular localisation}

Enrichment of subcellular fractions was evaluated using western blots and has been published previously [29]. We achieved separation and enrichment of sarcolemmal, mitochondrial/ endoplasmic reticulum, nuclear and cytosolic fractions with a small amount of nuclear contamination of sarcolemmal and mitochondrial/endoplasmic reticulum fractions.

Sarcolemma Individuals with obesity and type 2 diabetes had significantly greater total IMTG localised to the sarcolemma compared with those in the lean and athlete groups $(p=0.002$, Fig. 2a). Individuals with type 2 diabetes had greater saturated IMTG localised to the sarcolemma compared with all other groups $(p<0.0001$, Fig. $2 b)$. Combining all groups together, both total $(p=0.006$, Electronic supplementary material [ESM] Fig. 1) and saturated ( $p=0.002$; Fig. 3a) sarcolemmal IMTG were significantly inversely related to insulin sensitivity. When species specific differences were investigated, almost all individual sarcolemmal IMTG species were also significantly greater in individuals with obesity and/or type 2 diabetes compared with the lean and athlete groups (Fig. 4a).

Mitochondria/endoplasmic reticulum There were no significant differences in total or saturated IMTG localised to the mitochondria/endoplasmic reticulum between groups (Fig. 
Table 1 Study demographics

\begin{tabular}{|c|c|c|c|c|}
\hline \multirow[t]{2}{*}{ Variable } & \multicolumn{4}{|l|}{ Study group } \\
\hline & $\begin{array}{l}\text { Athlete } \\
(n=16)\end{array}$ & $\begin{array}{l}\text { Lean } \\
(n=14)\end{array}$ & $\begin{array}{l}\text { Obese } \\
(n=15)\end{array}$ & $\begin{array}{l}\text { T2D } \\
(n=12)\end{array}$ \\
\hline Sex (women/men) & $6 / 10$ & $6 / 8$ & $7 / 8$ & $5 / 7$ \\
\hline Age (year) & $42.5 \pm 5.0$ & $42.6 \pm 7.3$ & $42.0 \pm 5.5$ & $45.3 \pm 5.7$ \\
\hline BMI $\left(\mathrm{kg} / \mathrm{m}^{2}\right)$ & $23.1 \pm 2.0$ & $22.4 \pm 2.6$ & $35.4 \pm 4.3^{*^{\dagger}}$ & $34.8 \pm 6.2 *^{\dagger}$ \\
\hline Body fat (\%) & $16.9 \pm 5.3$ & $22.8 \pm 8.8$ & $36.7 \pm 7.5^{* \dagger}$ & $35.9 \pm 9.0 *^{\dagger}$ \\
\hline 2 h OGTT glucose $(\mathrm{mmol} / \mathrm{l})$ & $4.0 \pm 1.7$ & $5.2 \pm 0.9$ & $5.9 \pm 1.3$ & $16.9 \pm 4.2 * \dagger$ \\
\hline Fasting glucose $(\mathrm{mmol} / \mathrm{l})$ & $4.9 \pm 0.5$ & $5.0 \pm 0.3$ & $5.2 \pm 0.4$ & $9.6 \pm 2.4 *+*$ \\
\hline Fasting insulin (pmol/l) & $48.1 \pm 17.9$ & $63.1 \pm 31.6$ & $129.9 \pm 52.4^{\dagger}$ & $154.3 \pm 67.5^{* \dagger}$ \\
\hline Glucose $R_{\mathrm{d}}\left(\mathrm{mg} \mathrm{kg}^{-1} \min ^{-1}\right)$ & $12.4 \pm 2.6^{\dagger \dagger,+1+, \S \S \S}$ & 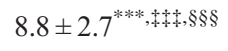 & $5.1 \pm 2.3^{* * *, \dagger \dagger, \S \S}$ & $2.3 \pm 1.4^{* * *, \dagger \dagger,+1 t}$ \\
\hline NEFAs $(\mathrm{mmol} / \mathrm{l})$ & $554 \pm 213$ & $599 \pm 274$ & $537 \pm 148$ & $593 \pm 155$ \\
\hline Triacylglycerols (mmol/l) & $3.7 \pm 1.1$ & $5.7 \pm 3.3$ & $6.9 \pm 3.2^{*}$ & $9.1 \pm 3.7^{\dagger \dagger}$ \\
\hline
\end{tabular}

Data have been previously reported [29]

Data are reported as mean $\pm \mathrm{SD}$

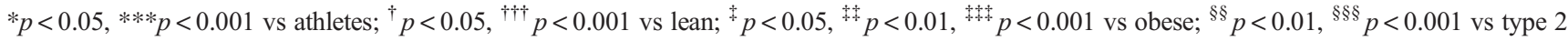
diabetes

T2D, type 2 diabetes

2a,b). Additionally, there were no individual species specific differences in IMTG localised to the mitochondria/ endoplasmic reticulum between groups (Fig. 4b). Further, neither total nor saturated species of mitochondrial/ endoplasmic reticulum IMTG were significantly related to insulin sensitivity (ESM Fig. 2 and ESM Fig. 3).
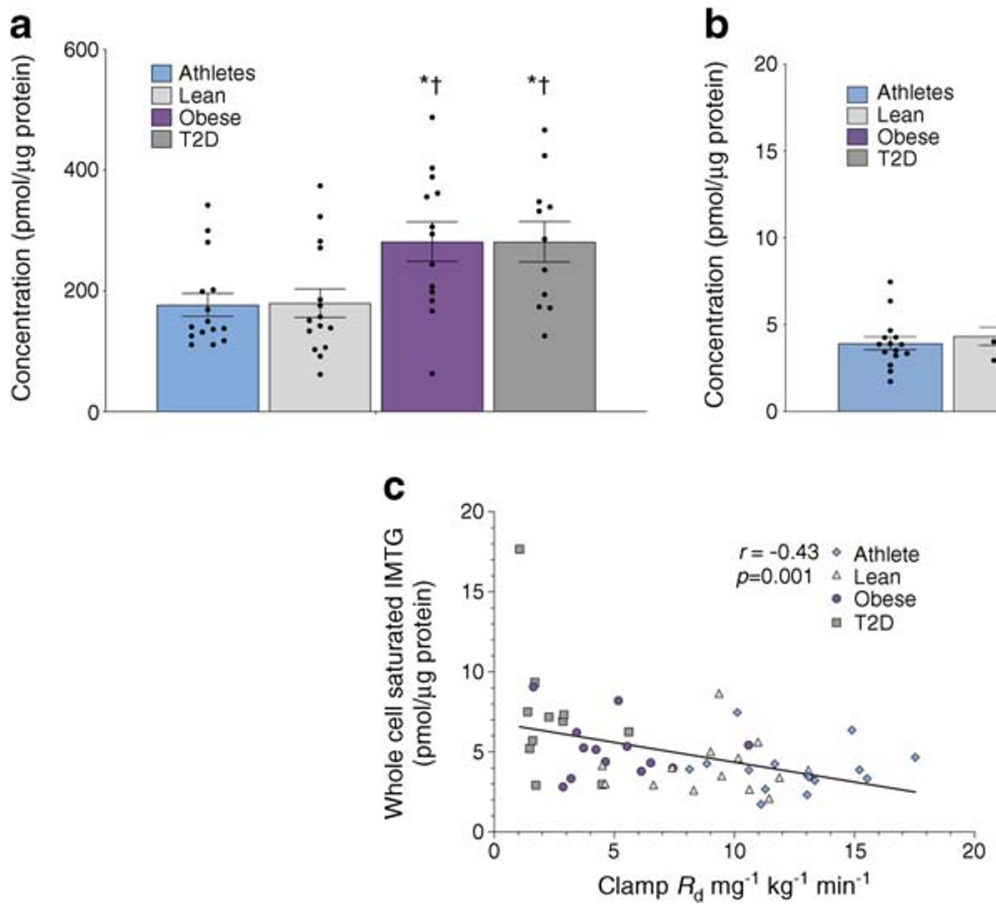

Fig. 1 Whole-cell total IMTG content (a), saturated IMTG content (b), and relationship between saturated IMTG content and insulin sensitivity (c) in endurance-trained athletes, lean and obese individuals, and
Nucleus In the nuclear compartment, individuals with type 2 diabetes accumulated significantly more IMTG than those in the lean and athlete group $(p=0.01)$, and significantly more saturated IMTG compared with all other groups $(p=0.0005)$ (Fig. 2a,b). When all groups were combined, total $(p=0.04$; ESM Fig. 4) and saturated ( $p=0.004$; Fig. 3b) IMTG

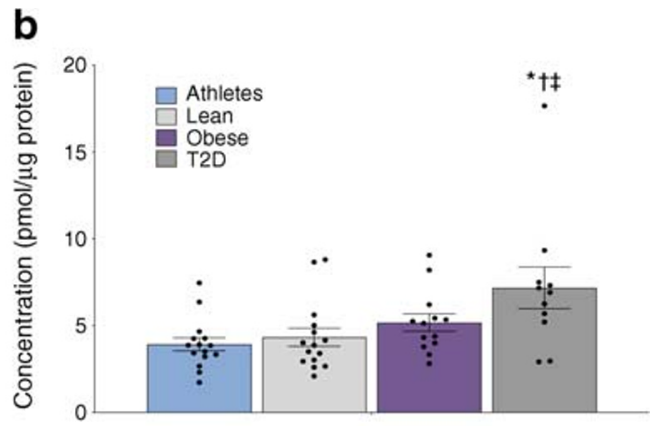

individuals with type 2 diabetes (T2D). Values are means \pm SEM. $* p<0.05$ vs athletes; ${ }^{\dagger} p<0.05$ vs lean; ${ }^{\star} p<0.05$ vs obese 


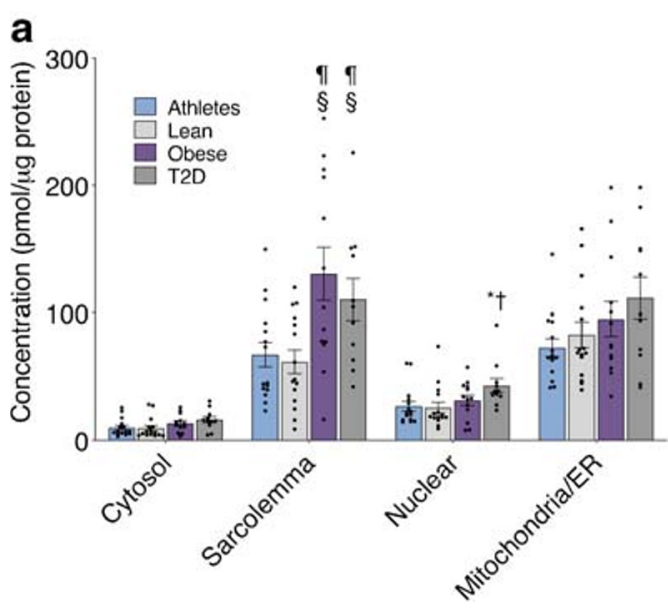

Fig. 2 Subcellular IMTG localisation normalised to protein content (a) and subcellular saturated IMTG localisation normalised to protein content (b) in endurance-trained athletes, lean and obese individuals, and

localised to the nucleus was significantly inversely related to insulin sensitivity. Differences in individual species between groups are shown in Fig. 4c.

Cytosol There were no significant differences in total cytosolic IMTG between groups (Fig. 2a). Total cytosolic IMTG was not related to insulin sensitivity (ESM Fig. 5). However, saturated cytosolic IMTG was significantly greater in individuals with type 2 diabetes compared with all other groups $(p<0.0001$, Fig. 2 b), and was inversely related to insulin sensitivity $(p=0.002)$ when all groups were combined (Fig. $3 c)$. Differences between groups for individual cytosolic IMTG species are shown in Fig. 4d.

\section{Relationships between localised IMTG and bioactive lipids}

We examined the relationships between sub-cellular concentrations of IMTG with DAG and ceramide in order to evaluate if IMTG degradation can explain the aetiology of localised bioactive lipid formation in human skeletal muscle. In the nuclear compartment, there was a significant positive relationship between total IMTG and total 1,2-DAG content ( $p=$ $0.005)$, as well as total IMTG and ceramide content $(p<0.0001)$ (Fig. 5a,b). There was also a significant positive relationship between total IMTG and ceramide content () in the cytosolic compartment $(p<0.0001$; Fig. 5c). Saturated IMTG was significantly positively related to disaturated 1,2DAG in the cytosolic compartment $(p<0.0001$; Fig. $5 \mathrm{~d})$. These relationships are consistent with channelling of IMTG degradation to bioactive lipid formation in some, but not all compartments. Specifically, our data indicate that nuclear IMTG promotes nuclear 1,2-DAG and ceramide formation, and cytosolic IMTG promotes cytosolic ceramide and 1,2DAG formation.

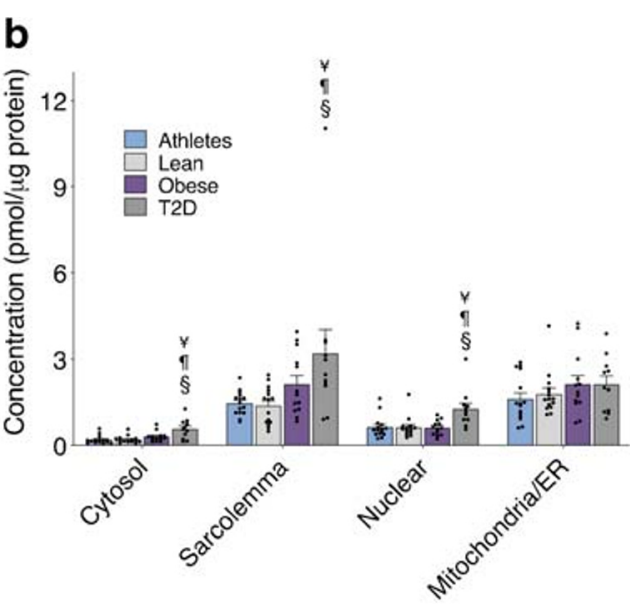

individuals with type 2 diabetes (T2D). Values are means \pm SEM. $* p<0.05,{ }^{\S} p<0.001$ vs athletes; ${ }^{\dagger} p<0.05,{ }^{\text {II }} p<0.001$ vs lean; $¥ p<0.001$ vs obese. ER, endoplasmic reticulum

\section{Dietary lipid intake}

We used a combination of the National Cancer Institute's Diet History Questionnaire II (DHQII) and erythrocyte phospholipid content to estimate habitual dietary lipid intake [46]. We found no differences in estimates of total daily energy, total fat, carbohydrate, protein or alcohol intake between groups (Table 2). However, total saturated fatty acid intake was significantly greater in individuals with type 2 diabetes compared with lean control participants and athletes, and in individuals with obesity compared with athletes $(p=0.008)$. The difference in saturated fatty acid intake in individuals with type 2 diabetes vs lean individuals and/or athletes was largely explained by alterations in the estimated intake of $\mathrm{C} 14: 0(p=$ $0.004), \mathrm{C} 16: 0(p=0.01)$ and $\mathrm{C} 18: 0(p=0.004)$ saturated fatty acids between these groups. Trans fat intake of 18:1 $(p=0.02)$ and 18:2 $(p=0.01)$ were significantly lower in athletes compared with individuals with obesity and type 2 diabetes (data not shown). However, there were no significant differences in the absolute or relative abundances of erythrocyte phospholipids between groups (data not shown). These data are mixed, but the dietary intake estimates suggest that individuals with type 2 diabetes habitually consumed significantly more saturated fat than individuals in all other study groups, which may explain alterations in saturated IMTG between groups.

\section{Discussion}

IMTG was initially thought to promote insulin resistance, but this relationship has not held up under closer scrutiny. Endurance-trained athletes and individuals with type 2 diabetes typically store similar amounts of IMTG, yet have highly divergent insulin sensitivity [5] and it has been suggested that 

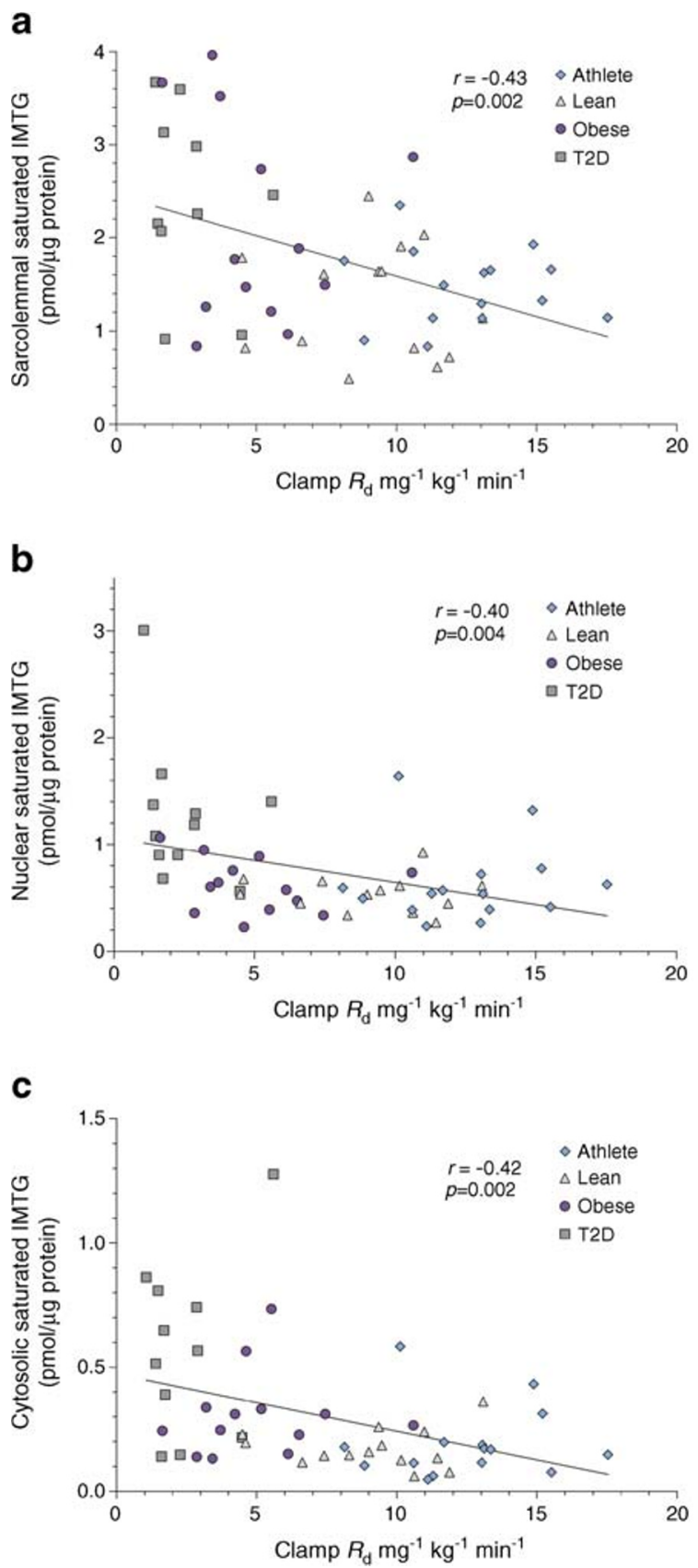

Fig. 3 Correlations between saturated IMTG localised to the sarcolemma (a), nucleus (b), and cytosol (c) with insulin sensitivity. T2D, type 2 diabetes

the disposal of fatty acids entering muscle into the IMTG pool protects against the development of insulin resistance [17, 47]. Adding to this complexity are studies indicating the significance of IMTG composition and localisation within skeletal muscle tissue, with saturated IMTG as well as IMTG in the subsarcolemmal compartment being related to decreased insulin sensitivity [33-36]. The purpose of this study was to analyse IMTG localisation within fractionated subcellular compartments of vastus lateralis muscle from humans spanning the physiological range of insulin sensitivity, providing a more detailed understanding of the complicated relationship between IMTG and insulin resistance. We found significantly more accumulation of sarcolemmal IMTG in individuals with obesity and type 2 diabetes, along with more nuclear IMTG accumulation in individuals with type 2 diabetes. IMTG in sarcolemmal and nuclear compartments were significantly negatively related to insulin sensitivity, but the strongest relationships were observed for saturated IMTG in sarcolemmal, nuclear and cytosolic compartments. IMTG localised to the mitochondrial/endoplasmic reticulum compartment were not different between groups and were not related to insulin sensitivity. In the nuclear and cytosolic compartments, there were significant positive relationships between IMTG and ceramide as well as 1,2-DAG, suggesting a role for IMTG in promoting bioactive lipid accumulation in these compartments. These data reveal that sarcolemmal and nuclear accumulation of IMTG negatively relates to insulin sensitivity, while mitochondrial IMTG accumulation appears to be neutral towards alterations in insulin sensitivity and may be a benign storage depot in the development of skeletal muscle insulin resistance. These data also indicate that saturated fatty acids stored as IMTG in the cytosolic, sarcolemmal and nuclear compartments may be uniquely deleterious towards insulin sensitivity.

While there are divergent reports in the literature [27], our data do agree with previous studies reporting a negative relationship between saturated IMTG and insulin sensitivity in humans $[24,48]$. The current data extend these previous observations to show saturated IMTG as being more strongly inversely related to insulin sensitivity than total IMTG in the whole cell and cytosolic, nuclear and sarcolemmal compartments. The explanation for this phenomenon is not clear; however, some hypotheses have emerged. Individuals with type 2 diabetes in this study had increased habitual intake of saturated fat, compared with the other three study groups. Population studies have reported that saturated fat intake is related to increased CVD risk and insulin resistance, and interventions replacing saturated with polyunsaturated fat decrease the risk of CVD and insulin resistance [49-51]. Therefore, it is possible that higher levels of saturated IMTG simply reflect increased dietary intake of saturated fat, and it is the global effect of a diet high in saturated fat that has an impact on insulin sensitivity, rather than total IMTG content.

Nevertheless, the impact of lipid composition on the complex processes of lipid synthesis, storage and turnover in skeletal muscle is not fully elucidated. It is known that unsaturated lipids are oxidised preferentially over saturated lipids [52]. This could result in channelling of saturated acyl groups into IMTG and may help explain decreased skeletal muscle lipid oxidation rates in obese populations [53]. Further, IMTG stores are constantly turning over [54, 55], with IMTG synthesis rates being positively related to insulin sensitivity [13-16]. High rates of IMTG synthesis appear to alter the intracellular localisation of DAG [14] and decrease muscle DAG content 

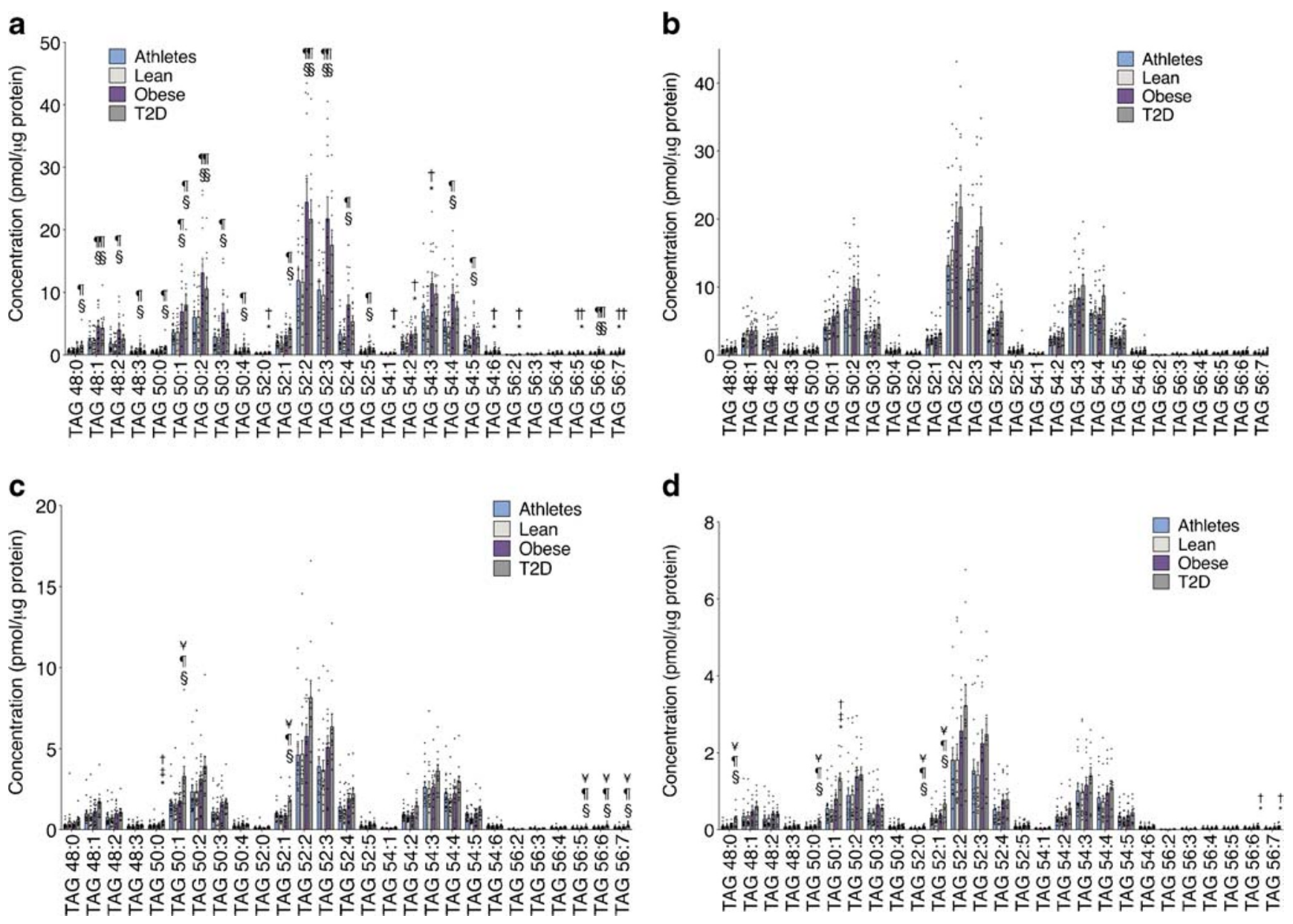

Fig. 4 IMTG species in sarcolemmal (a), mitochondria/endoplasmic reticulum (b), nuclear (c), and cytosolic (d) fractions from participants. Values are means \pm SEM. $* p<0.05,{ }^{\S} p<0.01$ vs athletes; ${ }^{\dagger} p<0.05,{ }^{\text {II }} p<0.01$ vs lean; ${ }^{\ddagger} p<0.05,{ }^{\ddagger} p<0.01$ vs obese. T2D, type 2 diabetes; TAG, triacylglycerol

[17]. However, during IMTG lipolysis, saturated IMTG stores will result in liberation of saturated acyl groups and contribute to the formation of saturated bioactive lipids, such as ceramides, that appear to play more negative roles in promoting insulin resistance [18-20]. Our data showing strong relationships between IMTG and total and disaturated 1,2-DAGs in nuclear and cytosolic compartments is consistent with the idea of 1,2-DAGs escaping the IMTG synthetic pathway to generate localised lipids, in line with data from in vitro and rodent models [56]. These data highlight the relationship between increased saturated IMTG accumulation and the composition of bioactive lipids. While detailed mechanisms explaining the relationship are not yet clear, saturated IMTG in cytosolic, nuclear and sarcolemmal compartments appear to be most robustly related to insulin resistance.

Another novel finding from this study is that there were no significant differences in mitochondrial/endoplasmic reticulum IMTG stores between the groups with varying degrees of insulin sensitivity. In fact, this was the only cellular compartment where total and saturated IMTG was not significantly related to insulin sensitivity. This suggests that the mitochondrial/endoplasmic reticulum compartment may be a safe place for triacylglycerol storage. This idea is supported by previous findings in which intermyofibrillar triacylglycerol stores were not significantly related or even positively related to insulin sensitivity [33-36]. The close proximity of IMTG to mitochondria has been suggested to facilitate oxidation of this lipid depot [40]. If true, channelling of IMTG acyl groups towards oxidation may prevent possible negative impacts on insulin sensitivity and explain the apparent neutrality of this IMTG location. We have also shown that lipid droplets do not remain in contact with the mitochondria/endoplasmic reticulum following fractionation [29]. Therefore, the fractionation procedure could have altered differences in mitochondrial/ endoplasmic reticulum lipids that exist in vivo.

Another possible explanation for what appears to be a limited impact of mitochondrial/endoplasmic reticulum IMTG on insulin sensitivity is that perhaps triacylglycerols measurement in this compartment simply reflects triacylglycerol storage in mitochondrial membranes. We previously published that the lipid droplet marker perilipin 2 is only found in the cytosol and sarcolemma when using the 

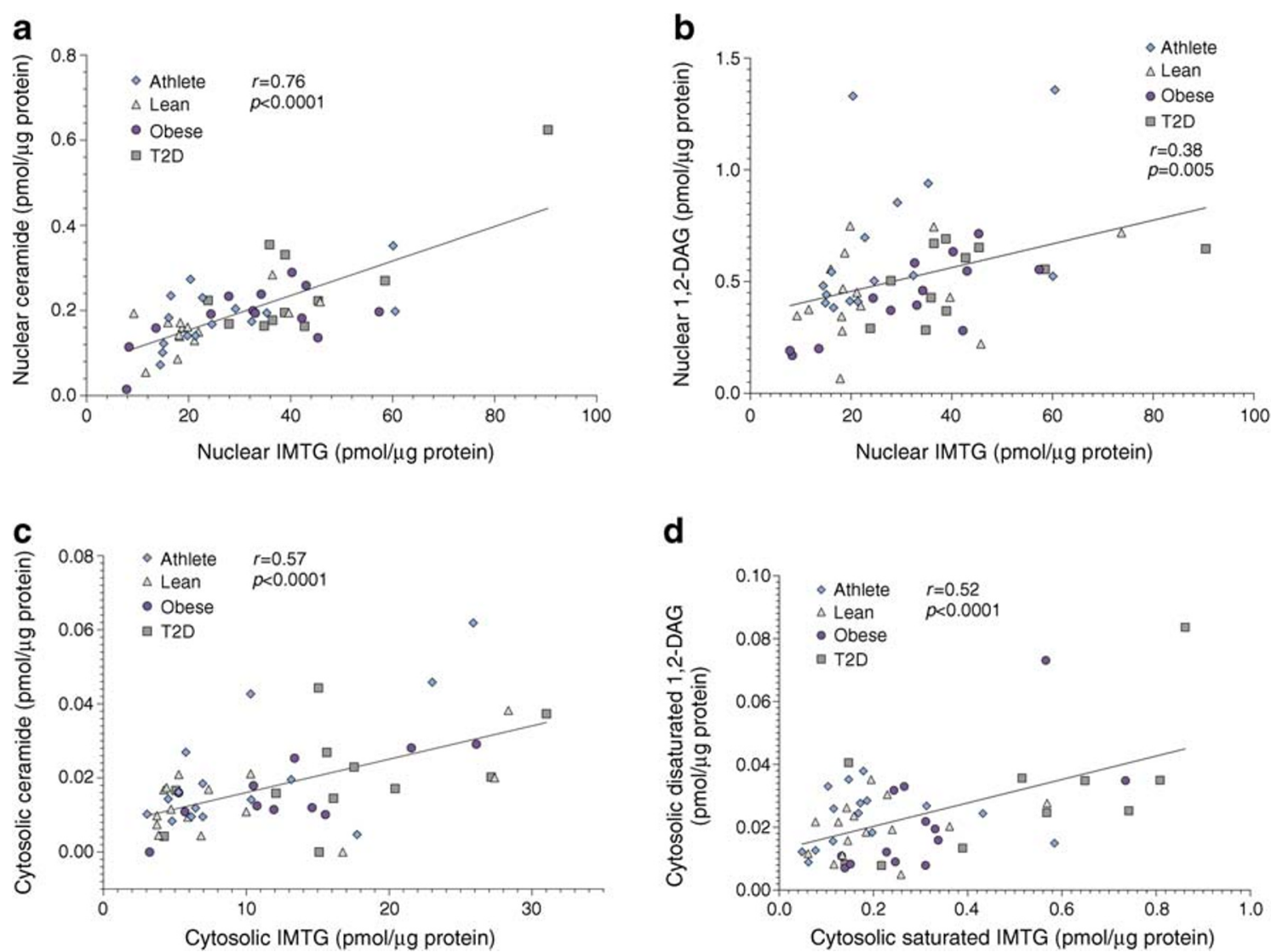

Fig. 5 Correlations between total nuclear IMTG and total nuclear ceramide (a) and 1,2-DAG (b). Correlations in the cytosolic compartment between total IMTG and total ceramide (c), and saturated IMTG and disaturated 1,2-DAG (d).T2D, type 2 diabetes

subcellular fractionation protocol used in this study [29]. Therefore, IMTG in the mitochondria/endoplasmic reticulum, as well as the nuclear compartments, do not appear to be stored in lipid droplets. If, instead, these IMTG molecules exist within the membranes of the organelles, it is possible that this IMTG does not have an impact on insulin sensitivity. These data also suggest that mitochondrial triacylglycerol content is similar between groups when normalised to protein content. Given endurance training increases mitochondrial volume density, the total content of IMTG in the mitochondrial/endoplasmic reticulum fraction would be expected to be greater in endurance-trained athletes as compared with the other groups.

Perhaps the most novel finding of the current work is that nuclear IMTG was increased in individuals with type 2 diabetes and that saturated IMTG in the nucleus was inversely related to insulin sensitivity. Interestingly, in vivo, myonuclei reside within the subsarcolemmal region of muscle and previous studies have shown that IMTG localised to the subsarcolemma is positively associated with insulin resistance and type 2 diabetes [33-36]. However, a more detailed understanding of the specific role of nuclear triacylglycerol in insulin resistance is entirely unknown. Nuclear lipids are known to have an impact on cell signalling as nuclear lipid droplets that can potentially regulate genomic function have been described [57, 58]. In hepatocytes, these nuclear lipid droplets colocalised with diacylglycerol $O$ acyltransferase 2 (DGAT2), allowing them to expand by synthesising triacylglycerol, similar to cytoplasmic lipid droplets [58]. We previously published that nuclear 1,2-DAGs were increased in endurance-trained athletes and were positively related to insulin sensitivity. Protein kinase $C \beta(\mathrm{PKC} \beta)$ is a DAG-sensitive isoform that phosphorylates histone $\mathrm{H} 3$ and could reveal a mechanism by which 1,2-DAGs that are generated from nuclear IMTG turnover could have an impact on gene expression [59]. Additionally, ceramides and their metabolites have been shown to directly modify transcription and gene expression in a variety of different cell types [60-62]. For example, ceramide synthesis alters the expression of sterolregulatory element-binding proteins (SREBPs), which regulate the transcription of genes involved in lipid biosynthesis. Our findings indicate that nuclear ceramides are positively associated with nuclear IMTG (Fig. 5a), and this accumulation of bioactive lipids that can alter gene expression may offer a mechanism for the relationship between insulin resistance and nuclear IMTG content. Combined, nuclear IMTG, along with ceramides and DAGs (as already reported [29]), may represent lipid pools that have an impact on nuclear function and, therefore, cellular gene expression. 
Table 2 Estimated habitual dietary intake

\begin{tabular}{|c|c|c|c|c|}
\hline & \multicolumn{4}{|l|}{ Study group } \\
\hline & $\begin{array}{l}\text { Athlete } \\
(n=16)\end{array}$ & $\begin{array}{l}\text { Lean } \\
(n=14)\end{array}$ & $\begin{array}{l}\text { Obese } \\
(n=15)\end{array}$ & $\begin{array}{l}\text { T2D } \\
(n=12)\end{array}$ \\
\hline Energy $(\mathrm{kJ})$ & $8477 \pm 5606$ & $7707 \pm 3071$ & $9460 \pm 2924$ & $9962 \pm 4025$ \\
\hline Carbohydrate (g) & $254 \pm 168$ & $221 \pm 98$ & $253 \pm 83$ & $264 \pm 114$ \\
\hline Protein $(g)$ & $80.7 \pm 56$ & $74.6 \pm 34$ & $96.0 \pm 25$ & $101.3 \pm 52$ \\
\hline Alcohol (g) & $8.1 \pm 6.1$ & $5.6 \pm 4.8$ & $9.0 \pm 14.0$ & $6.96 \pm 10.0$ \\
\hline Total fat (g) & $76.6 \pm 59$ & $73.0 \pm 29$ & $94.0 \pm 36$ & $101.9 \pm 41$ \\
\hline Saturated fat $(g)$ & $22.0 \pm 13.0$ & $23.0 \pm 8.6$ & $29.5 \pm 11.0 * *$ & $35.4 \pm 15.4 * * \dagger \dagger$ \\
\hline C4:0 (butanoic acid) & $0.54 \pm 0.33$ & $0.58 \pm 0.27$ & $0.66 \pm 0.33$ & $0.96 \pm 0.54 * *+$ \\
\hline C6:0 (hexanoic acid) & $0.29 \pm 0.20$ & $0.31 \pm 0.15$ & $0.33 \pm 0.17$ & $0.52 \pm 0.31 *+*$ \\
\hline C8:0 (octanoic acid) & $0.26 \pm 0.20$ & $0.23 \pm 0.12$ & $0.25 \pm 1.11$ & $0.37 \pm 0.20^{\dagger}$ \\
\hline C10:0 (decanoic acid) & $0.44 \pm 0.28$ & $0.44 \pm 0.21$ & $0.48 \pm 0.24$ & $0.70 \pm 0.40 * \dagger$ \\
\hline C12:0 (dodecanoic acid) & $0.78 \pm 0.47$ & $0.61 \pm 0.36$ & $0.68 \pm 0.34$ & $0.90 \pm 0.43$ \\
\hline C14:0 (tetradecanoic acid) & $2.01 \pm 1.12$ & $2.05 \pm 0.92$ & $2.53 \pm 1.04$ & $3.56 \pm 1.80 * * \dagger+$ \\
\hline C16:0 (hexadecanoic acid) & $13.7 \pm 7.7$ & $12.5 \pm 4.6$ & $16.2 \pm 6.0$ & $18.8 \pm 8.0^{\dagger \dagger}$ \\
\hline C17:0 (heptadecanoic acid) & $0.065 \pm 0.06$ & $0.057 \pm 0.03$ & $0.071 \pm 0.03$ & $0.076 \pm 0.04$ \\
\hline C18:0 (octadecanoic acid) & $5.53 \pm 3.14$ & $5.46 \pm 2.12$ & $7.33 \pm 2.75$ & $8.37 \pm 3.83 * * \dagger \dagger$ \\
\hline C20:0 (eicosanoic acid) & $0.32 \pm 0.37$ & $0.16 \pm 0.12$ & $0.19 \pm 0.10$ & $0.17 \pm 0.08$ \\
\hline C22:0 (docosanoic acid) & $0.45 \pm 0.59^{\dagger}$ & $0.14 \pm 0.15$ & $0.21 \pm 0.15$ & $0.18 \pm 0.15$ \\
\hline Monounsaturated fat (g) & $30.2 \pm 26.0$ & $28.3 \pm 12.3$ & $37.0 \pm 15.6$ & $38.6 \pm 15.0$ \\
\hline C16:1 (hexadecenoic acid) & $1.12 \pm 0.54$ & $1.11 \pm 0.45$ & $1.50 \pm 0.50$ & $1.81 \pm 0.89 * \dagger$ \\
\hline C18:1 (octadecanoic acid) & $33.8 \pm 24.9$ & $26.5 \pm 11.8$ & $34.6 \pm 15.0$ & $35.8 \pm 13.6$ \\
\hline C20:1 (eicosenoic acid) & $0.39 \pm 0.36^{\dagger}$ & $0.21 \pm 0.10$ & $0.29 \pm 0.15$ & $0.27 \pm 0.16$ \\
\hline C22:1 (docosenoic acid) & $0.05 \pm 0.03$ & $0.04 \pm 0.04$ & $0.04 \pm 0.04$ & $0.03 \pm 0.02$ \\
\hline Polyunsaturated fat (g) & $17.2 \pm 14.4$ & $14.7 \pm 7.8$ & $18.5 \pm 8.6$ & $17.5 \pm 7.1$ \\
\hline C18:2 (octadecadienoic acid) & $18.3 \pm 14.5$ & $12.8 \pm 6.8$ & $16.2 \pm 7.6$ & $15.4 \pm 6.3$ \\
\hline C18:3 (octadecatrienoic acid) & $1.54 \pm 0.75$ & $1.46 \pm 0.91$ & $1.70 \pm 0.97$ & $1.63 \pm 0.69$ \\
\hline $\begin{array}{l}\mathrm{C} 18: 4 \text { (octadecatetraenoic } \\
\text { acid) }\end{array}$ & $0.02 \pm 0.01$ & $0.01 \pm 0.01$ & $0.01 \pm 0.01$ & $0.01 \pm 0.01$ \\
\hline C20:4 (eicosatetraenoic acid) & $0.12 \pm 0.07$ & $0.10 \pm 0.06$ & $0.15 \pm 0.08$ & $0.14 \pm 0.07$ \\
\hline C20:5 (eicosapentaenoic acid) & $0.09 \pm 0.08$ & $0.05 \pm 0.05$ & $0.06 \pm 0.06$ & $0.04 \pm 0.03 *$ \\
\hline
\end{tabular}

Data are reported as mean $\pm \mathrm{SD}$

${ }^{*} p<0.05, * * p<0.01$ vs athletes; ${ }^{\dagger} p<0.05,{ }^{\dagger \dagger} p<0.01$ vs lean; ${ }^{*}<0.05$ vs obese

$\mathrm{T} 2 \mathrm{D}$, type 2 diabetes

We were surprised to find similar total IMTG content in athletes and lean control participants, rather than the greater content observed in athletes and individuals with type 2 diabetes, which has previously been reported by our group and others [ 5 , $6,14,36,63]$. There are several possible explanations for these results. Most of these previous cross-sectional studies used histochemical assessment of triacylglycerols with neutral lipid stains, in contrast to the biochemical assessment used in the current study. Biochemical vs histochemical methodologies do not generate identical results [64] and the differing methodology for measuring IMTG may influence the outcome. The lack of dietary control in this study may have also played a role in altering IMTG content relative to more controlled conditions. Previous studies from our lab provided a 3 day diet to volunteers and found similar IMTG content when comparing the muscle of athletes with individuals with obesity and type 2 diabetes [14]. It is also possible that the $48 \mathrm{~h}$ of rest could have had an impact on IMTG concentrations in the athlete group, and/or the athletes could have undereaten in order to maintain energy balance, which also could have lowered IMTG concentration.

A limitation of this study is that we did not have data for proximity between IMTG and mitochondria, so we are missing information regarding their physical co-localisation, which has been shown to be important in other studies [37]. Additionally, all participants with type 2 diabetes adhered to a 2 week washout period of diabetes medications to avoid the confounding effects on muscle lipid concentrations; however, it is possible that the wash out itself had an impact on IMTG localisation and 
accumulation. We are assuming that IMTG in the mitochondrial/ endoplasmic reticulum and nuclear fractions represent triacylglycerols within the membranes, and not those confined within a lipid droplet. The organic solvents in the lipid extraction should remove endogenous enzyme activity and physically separate acyl-CoA from DAG, so, while unlikely, it is possible that during the lipid extraction, DAGs may have been esterified by acyl groups to artificially increase triacylglycerol content in these fractions. Finally, as reported previously [29], the subcellular fractionation protocol results in a small amount of nuclear contamination that can be observed in the sarcolemmal and mitochondrial compartments, and it is possible that lipid carryover due to this contamination could occur and have an impact on these results.

Combined, these data reveal previously unknown differences in subcellular IMTG localisation in humans spanning the range of metabolic health. These data point to the importance of sarcolemmal and nuclear IMTG in insulin resistance and suggest saturated IMTG may be uniquely deleterious for muscle insulin sensitivity.

Data availability The datasets generated and/or analysed during the current study are available from the corresponding author on reasonable request.

Funding This work was partially supported by the National Institutes of Health General Clinical Research Center grant RR-00036, National Institute of Diabetes and Digestive and Kidney Diseases (NIDDK) grant to BCB (R01DK089170), T32 DK07658 grant, and the Colorado Nutrition Obesity Research Center grant P30DK048520.

Authors' relationships and activities The authors declare that there are no relationships or activities that may bias, or be perceived to bias, this work.

Contribution statement $\mathrm{BCB}$ is the study sponsor/funder of this work and, as such, had full access to all the data in the study and takes responsibility for the integrity of the data and the accuracy of the data analysis. DK performed participant testing, and helped interpret the data and write the manuscript. LP helped design the study, provided medical oversight, performed all biopsies, and helped interpret the data and write the manuscript. EM helped perform sample analysis and edited the manuscript. SZ helped perform sample analysis and edited the manuscript. SN performed participant testing, interpreted data and edited the manuscript. AS helped develop the subcellular fractionation protocol, helped with participant testing and edited the manuscript. AK performed participant testing, analysed samples and edited the manuscript. KH developed the lipidomics method, performed lipidomics analysis on all samples and edited the manuscript. JSB helped with statistical analysis for the entire study and edited the manuscript. BCB designed the study, performed participant testing, analysed and interpreted data and helped to write the manuscript. All authors gave final approval of the version of the manuscript to be published.

\section{References}

1. Pan DA, Lillioja S, Kriketos AD et al (1997) Skeletal muscle triglyceride levels are inversely related to insulin action. Diabetes 46:983-988. https://doi.org/10.2337/diab.46.6.983
2. Krssak M, Falk Petersen K, Dresner A et al (1999) Intramyocellular lipid concentrations are correlated with insulin sensitivity in humans: A 1H NMR spectroscopy study. Diabetologia 42:113116. https://doi.org/10.1007/s001250051123

3. Phillips DI, Caddy S, Ilic V et al (1996) Intramuscular triglyceride and muscle insulin sensitivity: Evidence for a relationship in nondiabetic subjects. Metabolism 45:947-950. https://doi.org/10.1016/ S0026-0495(96)90260-7

4. Perseghin G, Scifo P, De Cobelli F et al (1999) Intramyocellular triglyceride content is a determinant of in vivo insulin resistance in humans: A 1H-13C nuclear magnetic resonance spectroscopy assessment in offspring of type 2 diabetic parents. Diabetes 48 : 1600-1606. https://doi.org/10.2337/diabetes.48.8.1600

5. Goodpaster BH, He J, Watkins S, Kelley DE (2001) Skeletal muscle lipid content and insulin resistance: Evidence for a paradox in endurance-trained athletes. J Clin Endocrinol Metab 86:57555761. https://doi.org/10.1210/jcem.86.12.8075

6. Dube JJ, Amati F, Stefanovic-Racic M, Toledo FG, Sauers SE, Goodpaster BH (2008) Exercise-induced alterations in intramyocellular lipids and insulin resistance: The athlete's paradox revisited. Am J Physiol Endocrinol Metab 294:E882-E888. https:// doi.org/10.1152/ajpendo.00769.2007

7. Shaw CS, Shepherd SO, Wagenmakers AJ, Hansen D, Dendale P, van Loon LJ (2012) Prolonged exercise training increases intramuscular lipid content and perilipin 2 expression in type I muscle fibers of patients with type 2 diabetes. Am J Physiol Endocrinol Metab 303:E1158-E1165. https://doi.org/10.1152/ajpendo.00272.2012

8. Louche K, Badin PM, Montastier E et al (2013) Endurance exercise training up-regulates lipolytic proteins and reduces triglyceride content in skeletal muscle of obese subjects. J Clin Endocrinol Metab 98:4863-4871. https://doi.org/10.1210/jc.2013-2058

9. Bruce CR, Kriketos AD, Cooney GJ, Hawley JA (2004) Disassociation of muscle triglyceride content and insulin sensitivity after exercise training in patients with type 2 diabetes. Diabetologia 47:23-30. https://doi.org/10.1007/s00125-003-1265-7

10. Bruce CR, Thrush AB, Mertz VA et al (2006) Endurance training in obese humans improves glucose tolerance and mitochondrial fatty acid oxidation and alters muscle lipid content. Am J Physiol Endocrinol Metab 291:E99-E107. https://doi.org/10.1152/ ajpendo.00587.2005

11. Meex RC, Schrauwen-Hinderling VB, Moonen-Kornips E et al (2010) Restoration of muscle mitochondrial function and metabolic flexibility in type 2 diabetes by exercise training is paralleled by increased myocellular fat storage and improved insulin sensitivity. Diabetes 59:572-579. https://doi.org/10.2337/db09-1322

12. Helge JW, Stallknecht B, Drachmann T et al (2011) Improved glucose tolerance after intensive life style intervention occurs without changes in muscle ceramide or triacylglycerol in morbidly obese subjects. Acta Physiol 201:357-364. https://doi.org/10. 1111/j.1748-1716.2010.02180.x

13. Bergman BC, Perreault L, Hunerdosse DM, Koehler MC, Samek AM, Eckel RH (2010) Increased intramuscular lipid synthesis and low saturation relate to insulin sensitivity in endurance-trained athletes. J Appl Physiol 108:1134-1141. https://doi.org/10.1152/ japplphysiol.00684.2009

14. Bergman BC, Perreault L, Strauss A et al (2018) Intramuscular triglyceride synthesis: Importance in muscle lipid partitioning in humans. Am J Physiol Endocrinol Metab 314:E152-E164. https://doi.org/10.1152/ajpendo.00142.2017

15. Perreault L, Bergman BC, Hunerdosse DM, Eckel RH (2010) Altered intramuscular lipid metabolism relates to diminished insulin action in men, but not women, in progression to diabetes. Obesity 18:2093-2100. https://doi.org/10.1038/oby.2010.76

16. Perreault L, Bergman BC, Hunerdosse DM, Playdon MC, Eckel RH (2010) Inflexibility in intramuscular triglyceride fractional 
synthesis distinguishes prediabetes from obesity in humans. Obesity 18:1524-1531. https://doi.org/10.1038/oby.2009.454

17. Schenk S, Horowitz JF (2007) Acute exercise increases triglyceride synthesis in skeletal muscle and prevents fatty acid-induced insulin resistance. J Clin Investig 117:1690-1698. https://doi.org/10.1172/ JCI30566

18. Bergman BC, Hunerdosse DM, Kerege A, Playdon MC, Perreault L (2012) Localisation and composition of skeletal muscle diacylglycerol predicts insulin resistance in humans. Diabetologia 55: 1140-1150. https://doi.org/10.1007/s00125-011-2419-7

19. van Hees AM, Jans A, Hul GB, Roche HM, Saris WH, Blaak EE (2011) Skeletal muscle fatty acid handling in insulin resistant men. Obesity 19:1350-1359. https://doi.org/10.1038/oby.2011.10

20. Bergman BC, Brozinick JT, Strauss A et al (2016) Muscle sphingolipids during rest and exercise: A C18:0 signature for insulin resistance in humans. Diabetologia 59(4):785-798. https://doi. org/10.1007/s00125-015-3850-y

21. Turpin SM, Nicholls HT, Willmes DM et al (2014) Obesityinduced CerS6-dependent C16:0 ceramide production promotes weight gain and glucose intolerance. Cell Metab 20:678-686. https://doi.org/10.1016/j.cmet.2014.08.002

22. Turpin-Nolan SM, Hammerschmidt P, Chen W et al (2019) CerS1derived C18:0 ceramide in skeletal muscle promotes obesityinduced insulin resistance. Cell Rep 26:1-10. https://doi.org/10. 1016/j.celrep.2018.12.031

23. Raichur S, Wang ST, Chan PW et al (2014) CerS2 haploinsufficiency inhibits beta-oxidation and confers susceptibility to diet-induced steatohepatitis and insulin resistance. Cell Metab 20:687-695. https://doi.org/10.1016/j.cmet.2014.09.015

24. Manco M, Mingrone G, Greco AV et al (2000) Insulin resistance directly correlates with increased saturated fatty acids in skeletal muscle triglycerides. Metabolism 49:220-224. https://doi.org/10. 1016/S0026-0495(00)91377-5

25. Bergman BC, Perreault L, Hunerdosse D et al (2012) Novel and reversible mechanisms of smoking-induced insulin resistance in humans. Diabetes 61:3156-3166. https://doi.org/10.2337/db120418

26. Bergman BC, Perreault L, Hunerdosse DM, Koehler MC, Samek AM, Eckel RH (2009) Intramuscular lipid metabolism in the insulin resistance of smoking. Diabetes 58:2220-2227. https://doi.org/10. 2337/db09-0481

27. Helge JW, Dela F (2003) Effect of training on muscle triacylglycerol and structural lipids: A relation to insulin sensitivity? Diabetes 52:1881-1887. https://doi.org/10.2337/diabetes.52.8.1881

28. Helge JW, Wu BJ, Willer M, Daugaard JR, Storlien LH, Kiens B (2001) Training affects muscle phospholipid fatty acid composition in humans. J Appl Physiol 90:670-677. https://doi.org/10.1152/ jappl.2001.90.2.670

29. Perreault L, Newsom SA, Strauss A et al (2018) Intracellular localization of diacylglycerols and sphingolipids influences insulin sensitivity and mitochondrial function in human skeletal muscle. JCI Insight 3(3):e96805

30. Chung JO, Koutsari C, Blachnio-Zabielska AU, Hames KC, Jensen MD (2017) Intramyocellular ceramides: Sub-cellular concentrations and fractional de novo synthesis in postabsorptive humans. Diabetes 66(8):2082-2091. https://doi.org/10.2337/db17-0082

31. Nowotny B, Zahiragic L, Krog D et al (2013) Mechanisms underlying the onset of oral lipid-induced skeletal muscle insulin resistance in humans. Diabetes 62:2240-2248. https://doi.org/10.2337/ db12-1179

32. Jocken JW, Goossens GH, Boon H et al (2013) Insulin-mediated suppression of lipolysis in adipose tissue and skeletal muscle of obese type 2 diabetic men and men with normal glucose tolerance. Diabetologia 56:2255-2265. https://doi.org/10.1007/s00125-0132995-9
33. Nielsen J, Mogensen M, Vind BF et al (2010) Increased subsarcolemmal lipids in type 2 diabetes: Effect of training on localization of lipids, mitochondria, and glycogen in sedentary human skeletal muscle. Am J Physiol Endocrinol Metab 298: E706-E713. https://doi.org/10.1152/ajpendo.00692.2009

34. Nielsen J, Christensen AE, Nellemann B, Christensen B (2017) Lipid droplet size and location in human skeletal muscle fibers are associated with insulin sensitivity. Am J Physiol Endocrinol Metab 313:E721-E730. https://doi.org/10.1152/ajpendo.00062. 2017

35. Samjoo IA, Safdar A, Hamadeh MJ et al (2013) Markers of skeletal muscle mitochondrial function and lipid accumulation are moderately associated with the homeostasis model assessment index of insulin resistance in obese men. PLoS One 8:e66322. https://doi. org/10.1371/journal.pone.0066322

36. Daemen S, Gemmink A, Brouwers B et al (2018) Distinct lipid droplet characteristics and distribution unmask the apparent contradiction of the athlete's paradox. Mol Metab 17:71-81. https://doi. org/10.1016/j.molmet.2018.08.004

37. Devries MC, Samjoo IA, Hamadeh MJ et al (2013) Endurance training modulates intramyocellular lipid compartmentalization and morphology in skeletal muscle of lean and obese women. J Clin Endocrinol Metab 98:4852-4862. https://doi.org/10.1210/jc. 2013-2044

38. Koh HE, Ortenblad N, Winding KM, Hellsten Y, Mortensen SP, Nielsen J (2018) High-intensity interval, but not endurance, training induces muscle fiber type-specific subsarcolemmal lipid droplet size reduction in type 2 diabetic patients. Am J Physiol Endocrinol Metab 315:E872-E884. https://doi.org/10.1152/ ajpendo.00161.2018

39. Li Y, Lee S, Langleite $\mathrm{T}$ et al (2014) Subsarcolemmal lipid droplet responses to a combined endurance and strength exercise intervention. Physiol Rep 2(11):e12187. https://doi.org/10.14814/phy2. 12187

40. Tarnopolsky MA, Rennie CD, Robertshaw HA, FedakTarnopolsky SN, Devries MC, Hamadeh MJ (2007) Influence of endurance exercise training and sex on intramyocellular lipid and mitochondrial ultrastructure, substrate use, and mitochondrial enzyme activity. Am J Physiol Regul Integr Comp Physiol 292: R1271-R1278. https://doi.org/10.1152/ajpregu.00472.2006

41. Guo Z, Mishra P, Macura S (2001) Sampling the intramyocellular triglycerides from skeletal muscle. J Lipid Res 42:1041-1048

42. DeFronzo RA, Tobin JD, Andres R (1979) Glucose clamp technique: A method for quantifying insulin secretion and resistance. Am J Phys 237:E214-E223

43. Finegood DT, Bergman RN, Vranic M (1987) Estimation of endogenous glucose production during hyperinsulinemic-euglycemic glucose clamps. Comparison of unlabeled and labeled exogenous glucose infusates. Diabetes 36:914-924. https://doi.org/10.2337/ diab.36.8.914

44. Bielawski J, Szulc ZM, Hannun YA, Bielawska A (2006) Simultaneous quantitative analysis of bioactive sphingolipids by high-performance liquid chromatography-tandem mass spectrometry. Methods 39:82-91. https://doi.org/10.1016/j.ymeth.2006.05. 004

45. Benjamini Y, Hochberg Y (1995) Controlling the false discovery rate: A practial and powerful approach to multiple testing. J R Stat Soc B 57:289-300

46. Hodson L, Skeaff CM, Fielding BA (2008) Fatty acid composition of adipose tissue and blood in humans and its use as a biomarker of dietary intake. Prog Lipid Res 47:348-380. https://doi.org/10.1016/ j.plipres.2008.03.003

47. Liu L, Zhang Y, Chen N, Shi X, Tsang B, Yu YH (2007) Upregulation of myocellular DGAT1 augments triglyceride synthesis in skeletal muscle and protects against fat-induced insulin resistance. J Clin Invest 117:1679-1689 
48. Savage DB, Watson L, Carr K et al (2019) Accumulation of saturated intramyocellular lipid is associated with insulin resistance. $\mathrm{J}$ Lipid Res 60:1323-1332. https://doi.org/10.1194/jlr.M091942

49. Esrey KL, Joseph L, Grover SA (1996) Relationship between dietary intake and coronary heart disease mortality: Lipid research clinics prevalence follow-up study. J Clin Epidemiol 49:211-216. https://doi.org/10.1016/0895-4356(95)00066-6

50. Estruch R, Ros E, Salas-Salvado J et al (2013) Primary prevention of cardiovascular disease with a Mediterranean diet. N Engl J Med 368:1279-1290. https://doi.org/10.1056/NEJMoa1200303

51. Riccardi G, Giacco R, Rivellese AA (2004) Dietary fat, insulin sensitivity and the metabolic syndrome. Clin Nutr 23:447-456. https://doi.org/10.1016/j.clnu.2004.02.006

52. Leyton J, Drury PJ, Crawford MA (1987) Differential oxidation of saturated and unsaturated fatty acids in vivo in the rat. Br J Nutr 57: 383-393. https://doi.org/10.1079/BJN19870046

53. Kelley DE, Goodpaster B, Wing RR, Simoneau JA (1999) Skeletal muscle fatty acid metabolism in association with insulin resistance, obesity, and weight loss. Am J Phys 277:E1130-E1141

54. Sacchetti M, Saltin B, Osada T, van Hall G (2002) Intramuscular fatty acid metabolism in contracting and non-contracting human skeletal muscle. J Physiol 540:387-395. https://doi.org/10.1113/ jphysiol.2001.013912

55. Guo Z, Burguera B, Jensen MD (2000) Kinetics of intramuscular triglyceride fatty acids in exercising humans. J Appl Physiol 89: 2057-2064. https://doi.org/10.1152/jappl.2000.89.5.2057

56. Lee JS, Pinnamaneni SK, Eo SJ et al (2006) Saturated, but not n-6 polyunsaturated, fatty acids induce insulin resistance: Role of intramuscular accumulation of lipid metabolites. J Appl Physiol 100: 1467-1474. https://doi.org/10.1152/japplphysiol.01438.2005

57. Romanauska A, Kohler A (2018) The inner nuclear membrane is a metabolically active territory that generates nuclear lipid droplets. Cell 174:700-715. https://doi.org/10.1016/j.cell.2018.05.047
58. Ohsaki Y, Kawai T, Yoshikawa Y, Cheng J, Jokitalo E, Fujimoto T (2016) PML isoform II plays a critical role in nuclear lipid droplet formation. J Cell Biol 212:29-38. https://doi.org/10.1083/jcb. 201507122

59. Metzger E, Imhof A, Patel D et al (2010) Phosphorylation of histone $\mathrm{H} 3 \mathrm{~T} 6$ by $\mathrm{PKC} \beta_{\mathrm{I}}$ controls demethylation at histone $\mathrm{H} 3 \mathrm{~K} 4$. Nature 464:792-796. https://doi.org/10.1038/nature08839

60. Subbaramaiah K, Chung WJ, Dannenberg AJ (1998) Ceramide regulates the transcription of cyclooxygenase-2. Evidence for involvement of extracellular signal-regulated kinase/c-Jun Nterminal kinase and p38 mitogen-activated protein kinase pathways. J Biol Chem 273:32943-32949. https://doi.org/10.1074/jbc. 273.49.32943

61. Kelpe CL, Moore PC, Parazzoli SD, Wicksteed B, Rhodes CJ, Poitout V (2003) Palmitate inhibition of insulin gene expression is mediated at the transcriptional level via ceramide synthesis. J Biol Chem 278:30015-30021. https://doi.org/10.1074/jbc. M302548200

62. Patwardhan GA, Liu YY (2011) Sphingolipids and expression regulation of genes in cancer. Prog Lipid Res 50:104-114. https:// doi.org/10.1016/j.plipres.2010.10.003

63. Amati F, Dube JJ, Alvarez-Carnero E et al (2011) Skeletal muscle triglycerides, diacylglycerols, and ceramides in insulin resistance: Another paradox in endurance-trained athletes? Diabetes 60:25882597. https://doi.org/10.2337/db10-1221

64. Howald H, Boesch C, Kreis R et al (2002) Content of intramyocellular lipids derived by electron microscopy, biochemical assays, and ${ }^{1} \mathrm{H}-\mathrm{MR}$ spectroscopy. J Appl Physiol 92:22642272. https://doi.org/10.1152/japplphysiol.01174.2001

Publisher's note Springer Nature remains neutral with regard to jurisdictional claims in published maps and institutional affiliations. 